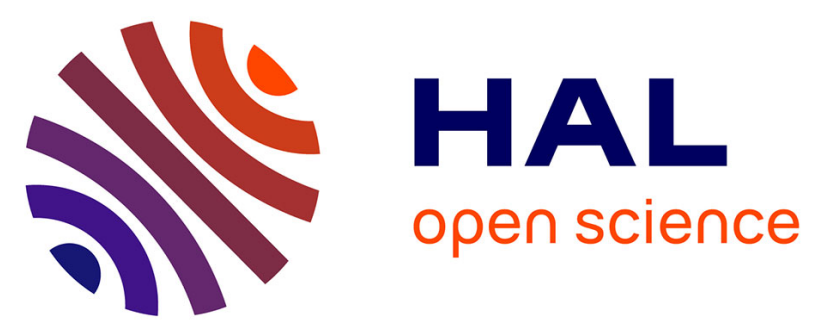

\title{
Honing the classification of high-risk endometrial cancer with inclusion of lymphovascular space invasion
}

\author{
Sofiane Bendifallah, Morgane Perrin, Lobna Ouldamer, Vincent Lavoué, \\ Geoffroy Canlorbe, Emilie Raimond, Delphine Hudry, Charles Coutant, \\ Olivier Graesslin, Cyril Touboul, et al.
}

\section{To cite this version:}

Sofiane Bendifallah, Morgane Perrin, Lobna Ouldamer, Vincent Lavoué, Geoffroy Canlorbe, et al.. Honing the classification of high-risk endometrial cancer with inclusion of lymphovascular space invasion. Surgical Oncology, 2017, 26 (1), pp.1-7. 10.1016/j.suronc.2016.11.001 . hal-01558318

\section{HAL Id: hal-01558318 \\ https://hal-univ-rennes1.archives-ouvertes.fr/hal-01558318}

Submitted on 12 Jul 2017

HAL is a multi-disciplinary open access archive for the deposit and dissemination of scientific research documents, whether they are published or not. The documents may come from teaching and research institutions in France or abroad, or from public or private research centers.
L'archive ouverte pluridisciplinaire HAL, est destinée au dépôt et à la diffusion de documents scientifiques de niveau recherche, publiés ou non, émanant des établissements d'enseignement et de recherche français ou étrangers, des laboratoires publics ou privés. 
1 Honing the classification of high-risk endometrial cancer with inclusion of lymphovascular space invasion

SOFIANE BENDIFALLAH (M.D) ${ }^{1,2}$, Morgane PERRIN (M.D) ${ }^{1}$, Lobna OULDAMER (M.D) ${ }^{3}$, Vincent LAVOUE (M.D, PhD) ${ }^{4}$, Geoffroy. CANLORBE (M.D) ${ }^{1}$, Emilie RAIMOND (M.D) ${ }^{5}$, Delphine HUDRY (M.D) ${ }^{6}$, Charles COUTANT (M.D, PhD) ${ }^{6}$, Olivier GRAESSLIN (M.D, PhD) ${ }^{5}$, Cyril TOUboul (M.D, PhD) ${ }^{7}$, Pierre COllinet ${ }^{8}$, Emile DARAï (M.D, PhD) ${ }^{1,9}$, Marcos BALLESTER (M.D, PhD) ${ }^{1,9}$

For the Groupe de Recherche FRANCOGYN

1. Department of Gynaecology and Obstetrics, Tenon University Hospital, Assistance Publique des Hôpitaux de Paris (AP-HP), University Pierre and Marie Curie, Paris 6, Institut Universitaire de Cancérologie (IUC), France.

2. INSERM UMR_S_707, "Epidemiology, Information Systems, Modeling", University Pierre and Marie Curie, Paris 6, France;

3 Department of Obstetrics and Gynaecology, Centre hospitalier régional universitaire de Tours, hôpital Bretonneau, Tours, France.

4 CRLCC Eugène-Marquis, service de gynécologie, CHU de Rennes, université de Rennes 1,

5 Department of Obstetrics and Gynaecology, Institute Alix de Champagne University Hospital, Reims, France.

6 Centre de lutte contre le cancer Georges François Leclerc, Dijon, France.

7 Department of Obstetrics and Gynaecology, Centre Hospitalier Intercommunal, Créteil, France.

8 Department of Obstetrics and Gynecology, Centre Hospitalier Régional Universitaire, Lille, France.

9. INSERM UMR_S_938, University Pierre et Marie Curie, Paris 6, France 
Corresponding Author:

28

Bendifallah Sofiane MD,

Service de Gynécologie-Obstétrique

30

Hôpital Tenon, 4 rue de la Chine, 75020 Paris, France

Phone: 33156017318 ;

32 Fax: 33156017317 ;

33 E-mail: sofiane.bendifallah@aphp.fr

The authors report no conflict of interest.

No source of financial support for the research

38

40

41

42

43

44

Short version of title : Classification for high-risk endometrial cancer

\section{HIGHLIGHTS}

- LVSI status remains a strong prognostic factor in high-risk ECs

- LVSI could be considered in future trials to guide decision-making in high-risk ECs 
46

47

48

49

50

51

52

53

54

55

56

57

58

59

60

61

62

63

64 65

66

\section{Abstract}

Objectives: The purpose of this study was to analyse the clinical impact of LVSI status in a large French multicentre cohort of women with high-risk ECs according to the ESMO classification.

Methods: Data of 258 women with high-risk EC who received primary surgical treatment between January 2001 and December 2012 were abstracted from prospective multicentre database. The end points were the recurrence and the lymph node metastasis (LNM) rates. Recurrence free survival (RFS) and overall survival (OS) were analyzed.

Results: The recurrence and LNM rates rates in the whole population were $32.9 \%$ and $34.5 \%$, respectively. The median follow-up and initial recurrence times were 27 (range: 1-151) and 23.5 (range: 1-151) months, respectively. The respective 3-year RFS rates according to the LNM and LVSI status were, 78.3\% (95\% CI, 70.1-87.3), 53.7\% (95\% CI, 40.8-70.6), 65.5\% (95\% CI, 46.193.2), 43.5\% (95\% CI, 30.3-62.3) for women with no LN metastasis/no LVSI; no LN metastasis/ LVSI present; LN metastasis/no LVSI; LN metastasis/ LVSI present, respectively $(\mathrm{p}=0.0005$; Figure 1).

Conclusions: LVSI status remains a strong prognostic factor in high-risk ECs associated with a higher recurrence rate and lower RFS and OS whatever the histological type and lymph node status. It could thus be considered in future trials to guide decision-making about adjuvant therapy in highrisk ECs 


\section{Introduction:}

Endometrial cancer (EC) is the most frequent gynaecological cancer in developed countries and ranks overall as the fourth cancer in women (after breast, lung \& bronchus and colon \& rectum). The estimated number of new cases in the United States in 2015 was 54900 with an estimated death rate of 10200 (7th cancer in terms of lethality) [1, 2]. There were nearly 100000 newly diagnosed cases in Europe in 2012 with an age standardised incidence of 13.6 per 100000 women [3].

Most cases of EC are diagnosed at an early stage for which prognosis is very good. However, the European Society for Medical Oncology (ESMO) classification describes a high-risk group with heterogeneous types and grades of EC including endometrioid (type 1), stage IB of the International Federation of Obstetrics and Gynecology (FIGO) classification, grade 3 tumours (type 1/G3ECs), non-endometrioid tumours (type 2) and advanced stages whatever the histological type [3]. These women have a poorer prognosis with an increased risk of metastatic disease and recurrences and represent most of the EC-related deaths. Overall survival and recurrence rates differ widely from one study to another with 5-year survival rates varying between 33 and $79 \%$ [4, 5].

Pathological type, myometrial infiltration and nodal status are the three major prognostic factors that are currently used worldwide to standardise treatment strategy, decision-making and clinical trial design for women at high risk $[6,7]$. In this specific setting, the lymphovascular space involvement (LVSI) status has been reported as a major prognostic factor [8], especially for the intermediate-risk group, impacting surgical management and indications for adjuvant therapies. However, few data exist about its value in women at high risk for whom the rationale for adjuvant treatment remains somewhat blurred $[3,9-11]$, especially for women with presumed FIGO stage 1 high-risk EC with no surgical nodal staging or with surgical nodal staging/node negative.

Hence, the purpose of this study was to analyse the clinical impact of LVSI status in a large French multicentre cohort of women with high-risk ECs. 


\section{Materials and methods}

\section{Study population}

Data of women with histologically proven EC defined as high risk according to the ESMO classification [3] (i.e., stage IB, grade 3 with endometrioid type 1; stage I with non-endometrioid type; advanced stages whatever the histological type) who received primary surgical treatment between January 2001 and December 2012 were abstracted from seven institutions with maintained EC databases in France (Tenon University Hospital, Reims University Hospital, Dijon Cancer Center, Rennes University Hospital, Lille University Hospital, Tours University Hospital, and Creteil University Hospital) and from the Senti-Endo trial [12]. All the women had given informed written consent to participate in the study. The research protocol was approved by the Institutional Review Board of the French College of Obstetrics and Gynaecology (CEROG 2014-GYN-020).

All enrolled women underwent preoperative abdomino-pelvic magnetic resonance imaging (MRI) unless contraindicated, in which case a computed tomography (CT) scan was performed. The following clinical, surgical and pathological data were collected: age, body mass index (BMI; calculated as weight in kilograms divided by the square of height in meters), surgical procedure, nodal staging, final pathological analysis (histological type and grade, depth of myometrial invasion, and LVSI status) and adjuvant therapies. All women were classified according to the FIGO 2009 classification [13] after final pathological analysis.

\section{Histological characteristics and ESMO risk groups}

In line with the ESMO guidelines, histological type 1 EC includes endometrioid tumours of any histological grade and histological type 2 includes clear cell adenocarcinomas, serous adenocarcinomas and carcinosarcoma [3]. Grade 3 tumours are those with more than 50\% of nonsquamous, non-morular growth pattern [14]. In addition to the non-squamous solid growth component, a markedly atypical nuclear pattern incongruous for the architectural grade could increase the final tumour grade by one. A tumour is considered LVSI positive when tumour emboli 
are found within a space clearly lined by endothelial cells on a haematoxylin and eosin (H\&E)stained section [15].

\section{Treatment and follow-up}

Women with histological proven EC had undergone primary surgical treatment including at least total hysterectomy with bilateral salpingo-oophorectomy. Some aspects of the management of high-risk EC changed within the study period: before 2010, nodal staging included pelvic (P-LND) +/- para-aortic lymph node dissection (PA-LND); after 2010, both pelvic and para-aortic lymphadenectomy were recommended. Surgery was performed according to the Institut National du Cancer (INCa) guidelines [14]. Adjuvant therapy was administered on an individual basis at the discretion of a multidisciplinary committee, based on the INCa guidelines and included vaginal brachytherapy (VBT) and/or external beam radiotherapy (EBRT) and/or chemotherapy (CT) and clinical follow-up [16]. Clinical follow-up consisted of physical examinations and the use of imaging techniques according to the findings. Follow-up visits were conducted every 3 months for the first 2 years, every 6 months for the following 3 years, and once a year thereafter.

\section{Recurrence event and recurrence-free survival}

Disease recurrence was diagnosed by biopsy or imaging techniques. Time-to-event analyses were calculated from the date of primary surgery as the starting point and women who were alive and without recurrence were censored at the date of last follow-up. Data for survival curves were calculated using the Kaplan-Meier method with log-rank test. Recurrence free survival (RFS) and overall survival (OS) were analyzed. Effects were expressed as hazard ratios with $95 \%$ confidence intervals as appropriate. Cox proportional hazard models included established prognostic factors: pathological type, adjuvant therapies, and nodal and LVSI status.

\section{Other analyses}

Women, tumour and treatment characteristics were analysed using Chi-square statistics or Fisher's exact test in case of categorical and t-test or analysis of variance (ANOVA) for continuous 
144 variables. Values of $\mathrm{P}<0.05$ were considered to denote significant differences. Data were managed

145 with an Excel database (Microsoft, Redmond, WA, USA) and analysed using the R 2.15 software, 146 available online.

147 
$\underline{\text { Results: }}$

149

150

151

152

153

154

155

156

157

158

159

160

161

162

163

164

165

166

167

168

169

170

171

172

\section{Characteristics of the study population}

During the study period, 258 women with high-risk EC were documented as having received primary surgical treatment and nodal staging according to the following distribution: Tenon University Hospital (45/258; 17.4\%), Tours University Hospital (42/258; 16.3\%), Dijon Cancer Center (38/258; 14.7\%), Creteil Hospital (33/258; 12.8\%), Reims University Hospital (23/258; 9.0\%), Rennes University Hospital (26/258; 10.1\%), Jeanne de Flandre University Hospital $(21 / 258 ; 8.1 \%)$, and Senti-Endo trial $(30 / 258 ; 11.6 \%)$. The median age of the women was 66.0 years (range 31-91 years) and the BMI $27.7 \mathrm{kgm}^{2}$ (range 16.8-50.6). Final histological types 1 and 2 were found in 53.1\% (137/258) and 46.9\% (121/258) of cases, respectively. The demographics and clinicopathological characteristics of the whole cohort are reported in Table 1. One hundred and twenty-seven women (49.2\%) were found to have LVSI on final histology. Epidemiological, surgical, histological, and outcome characteristics of the women according to LVSI status are reported in Table 2 .

\section{Recurrence rate and lymph node metastasis (LNM) rates according to prognostic subgroup}

The recurrence rate in the whole population was $32.9 \%(85 / 258)$. When comparing women with and without LVSI, the recurrence rates were $42.5 \%(54 / 127)$ and $23.7 \%(31 / 131)$, respectively $(\mathrm{p}=0.001)$

The LNM rate in the whole population was $34.5 \%$ (89/258). When comparing women with and without LVSI, the LNM rates were 52.0\% (66/127) and 17.6\% (23/131), respectively $(\mathrm{p}<0.001)$

When considering each subgroup according to the LN and LVSI status, the recurrence rates were $22.2 \%(24 / 08), 41 \%(25 / 61), 30.4 \%(7 / 23), 43.9 \%(29 / 66)$, for women with no LN metastasis/no LVSI, no LN metastasis/ LVSI present; LN metastasis/no LVSI, LN metastasis/ LVSI present, respectively $(\mathrm{p}=0.01)$. 


\section{ACCEPTED MANUSCRIPT}

\section{RFS and OS according to each prognostic subgroup.}

The median follow-up and initial recurrence times were 27 (range: 1-151) and 23.5 (range: 1151) months, respectively.

The respective 3-year RFS rates according to the LVSI status were 76.1\% (95\% CI, 68.484.8) and 45.5\% (95\% CI, 35.8-57.9) for women with or without LVSI $(\mathrm{p}<0.0001)$.

The respective 3-year RFS rates according to the LNM and LVSI status were, $78.3 \%$ (95\% CI, 70.1-87.3), 53.7\% (95\% CI, 40.8-70.6), 65.5\% (95\% CI, 46.1-93.2), 43.5\% (95\% CI, 30.3-62.3) for women with no LN metastasis/no LVSI; no LN metastasis/ LVSI present; LN metastasis/no LVSI; LN metastasis/ LVSI present, respectively ( $\mathrm{p}=0.0005$; Figure 1).

The 3-year OS for the whole population was 77.8\% (95\% CI, 58.2-85.8). The respective 3year OS rates according to the LVSI status were $87.2 \%(95 \% \mathrm{CI}, 80.8-94.1)$ and $67.2 \%(95 \% \mathrm{CI}$, 58.1-77.8) $(\mathrm{P}<0.0001)$ women with or without LVSI.

The respective 3-year OS rates according to the LNM and LVSI status were, $87.3 \%$ (95\% CI, 80.5-94.7), 70.7\% (95\% CI, 58.2-85.8), 84.2\% (95\% CI, 65.3-1), and 64.3\% (95\% CI, 51.8-79.8) for women with no LN metastasis/no LVSI, no LN metastasis/ LVSI present, LN metastasis/no LVSI, LN metastasis/ LVSI present, respectively $(\mathrm{p}=0.0004)$.

\section{Treatment}

\section{Lymph node dissection (LND) staging}

Complete P-PA LND was performed in $28.3 \%$ of the cases. The respective recurrence rates according to complete P-PA LND and P-LND were $34.2 \%(25 / 73)$ and $32.4 \%(60 / 185)$, respectively, $(\mathrm{p}=0.8948)$. The respective 3 -year RFS according to the P-PA-LND and P-LND $56.5 \%(95 \%$ CI, 43.6-73.3) and 65.7\% (95\% CI, 58.4-73.8), respectively, $(\mathrm{p}=0.276)$. The respective 3-year OS rates according to the P-PA-LND and P-LND were 82.6\% (95\% CI, 72.7-93.9) and $76.6 \%(95 \%$ CI, 70.0-83.9) $(\mathrm{p}=0.994)$.

\section{Adjuvant therapy}


Adjuvant therapy assignment according to LN and LVSI status is reported in figure 3 . A 199 significant difference in adjuvant therapy assignment was found depending on the LN and LVSI status $(p<0.0001)$. No difference in adjuvant therapy assignment was found between the two subgroups of women with no LN metastasis/ LVSI present and LN metastasis/no LVSI $(\mathrm{p}=0.2241)$.

Multivariate analysis.

In a multivariate analysis including the pathological type, adjuvant therapies, nodal status, and 204 LVSI status we found that adjuvant therapies and LVSI status were independently correlated to 3205 year RFS (Table 3). 
The results of the current study show that LVSI status remains a strong prognostic factor in high-risk ECs, independently of histological type and lymph node status. It could thus constitute an

210 effective tool for identifying a subset of women with poorer prognosis.

In the past decade, LVSI status has progressively gained importance as an independent prognostic factor for women with early-stage EC, especially for women in low- and intermediaterisk groups $[15,17,18]$. To our knowledge, few data exist on its prognostic value for high-risk ECs $[7,8,19]$. Furthermore, existing reports are restrictive and conflicting because of sample size, treatment heterogeneity (indications for nodal staging and adjuvant therapies), and definitions of risk groups for recurrence [20,21]. Previous studies have suggested that LVSI status is the strongest predictor of adverse outcome for both early- (stages I/II disease) and advanced-stage EC (stages III/IV) [7, 8, 19] and its prognostic value is supported by the current ESMO-ESGO-ESTRO guidelines [3]. Indeed, a new high-intermediate risk group has been identified and includes women from the low-intermediate risk group with LVSI [3]. For high-risk ECs, however, the LVSI status is not used as a prognostic factor and indications for adjuvant therapy are currently exclusively based on the histological type and FIGO stage (including lymph node status). In the study we report here, we demonstrate that LVSI status is correlated with the recurrence rate, 3-year RFS and OS, independently of the LN status. We thus believe that combining LVSI status with existing factors may identify an additional subset of women with high-risk EC who have poorer prognosis and require adjuvant therapies [22-24].

Several risk classifications for recurrence have been introduced worldwide to standardise surgical and adjuvant therapeutic management for high-risk ECs [3, 9-11, 25]. However, a debate about whether type 1/G3ECs should be classified with type 2 ECs as high-risk ECs has been generated. Several authors justify the inclusion of type 1/G3ECs in the high-risk group due to the frequency of their coexistence and similarities in clinical characteristics and molecular aspects of 
232 G3EC and type 2 cancers. [20, 22, 26, 27]. While the recent ESMO-ESGO-ESTRO guidelines

have validated the incorporation of type 1/G3ECs as high-risk ECs [3], other major classifications $[9,11,28,29]$ used to design clinical trials and adjuvant therapy management exclude the type 1/G3ECs located to corpus uteri from the high-risk group. Hence, indications for treatment strategies differ substantially between authors and countries leading to widely differing practice patterns [3, 9-11, 28]. In the current study, according to European guidelines, we proposed a combination of pathological type 1 and 2 to study the value of LVSI. We found no difference in the recurrence rate and the 3-year RFS between type 1 and 2 high-risk ECs. Moreover, we found that LVSI had the same clinical impact in women at high risk whatever the histological type.

There is a persistent debate about the rationale of pelvic radiotherapy and adjuvant chemotherapy in the standard management of high-risk ECs. In this specific setting, several ongoing clinical trials are assessing the place of chemoradiation, EBRT and chemotherapy alone in high-risk ECs [3]. Although chemotherapy would appear to benefit women at high risk with LNM, its indication in women without LNM is debatable. Indeed, the ESMO-ESGO-ESTRO guidelines recently recommended the following approach for women with type 1 high-risk EC with negative nodal staging: (i) adjuvant EBRT to decrease loco-regional recurrence, (ii) adjuvant brachytherapy as an alternative to decrease vaginal recurrence and (iii) adjuvant systemic therapy (currently under investigation). However, these guidelines do not take the LVSI status into account [3]. In the current study, we hypothesized that the management of women at high risk but without LNM could be improved by including the LVSI status. We found that LVSI may be a major prognostic factor for this subgroup of women, as women who were LVSI positive/node negative had a poorer prognosis than those with nodal metastases. Such differences could be explained by either the LVSI status itself or the lower rate of assignment of adjuvant therapies (especially chemotherapy) for women who were LVSI positive/node negative. Future trials evaluating the place of adjuvant chemotherapy for this subgroup of women should therefore consider the LVSI status as a decision 
criterion. Another situation concerns women with type 1 high-risk EC without nodal staging (either because of discrepancies between preoperative and final histology or because the woman was unable to undergo complete nodal staging due to multiple comorbidities) $[30,31]$. For these women, adjuvant EBRT is recommended, while sequential adjuvant chemotherapy could be an option [3]. Here again, LVSI status may be a good tool to select women for chemotherapy. Finally, for women who have high-risk type 2 EC (serous and clear cell adenocarcinoma) and are node negative, the place of adjuvant chemotherapy remains uncertain (level of evidence III) [3]. Although LVSI status is considered for women with stage IA this is not the case for those with stage IB. Once again, for this subgroup of women, we found a lower RFS and OS when the LVSI was positive implying that adjuvant chemotherapy could be important even in the absence of LNM.

Several limits of the study deserve to be mentioned. First, we cannot exclude bias linked to its retrospective nature. Second, the median follow-up for recurrence was relatively short. However, the majority of recurrences $(74 \% ; 63 / 85)$ occurred during the two 2 years of follow up. In addition, our median time of follow up is consistent with previous studies evaluating the prognosis of highrisk ECs [22-24]. Third, during the data collection period, modifications occurred in staging modalities (FIGO classification), and the indications for nodal staging and for adjuvant therapies. In the current study only $28.3 \%$ underwent a P-PA LND, while a P-LND was performed in all cases. This low rate can be explained by: i) PA -LND was not systematically recommended in France for high-risk patients before 2010; ii) patients in whom there was a discrepancy between pre- and postoperative risk groups did not systematically undergo secondary PA-LND, mainly due to associated morbidities [32]. However, we found no improvement in the survival rates between women who underwent complete nodal staging and those who underwent exclusive P-LND.

LVSI appears to be a major prognostic factor in high-risk ECs associated with a higher recurrence rate and lower RFS and OS whatever the histological type. LVSI should be considered in future trials to guide decision-making about adjuvant therapy in high-risk ECs, whatever the 
282 histological type or nodal status.

283

284

285

Conflict of interest statement

286

No authors have conflict of interests.

287 


\section{$\underline{\text { References }}$}

1. Sheikh MA, Althouse AD, Freese KE et al. USA endometrial cancer projections to 2030: should we be concerned? Future Oncol. Lond. Engl. 2014; 10(16):2561-2568.

2. Siegel RL, Miller KD, Jemal A. Cancer statistics, 2015. CA. Cancer J. Clin. 2015; 65(1):5-29.

3. Colombo N, Creutzberg C, Amant F et al. ESMO-ESGO-ESTRO Consensus Conference on Endometrial Cancer: diagnosis, treatment and follow-up $\dagger$. Ann. Oncol. Off. J. Eur. Soc. Med. Oncol. ESMO 2016; 27(1):16-41.

4. Cirisano FD, Robboy SJ, Dodge RK et al. The outcome of stage I-II clinically and surgically staged papillary serous and clear cell endometrial cancers when compared with endometrioid carcinoma. Gynecol. Oncol. 2000; 77(1):55-65.

5. Boruta DM, Gehrig PA, Fader AN, Olawaiye AB. Management of women with uterine papillary serous cancer: a Society of Gynecologic Oncology (SGO) review. Gynecol. Oncol. 2009; 115(1):142-153.

6. Alektiar KM, McKee A, Lin O et al. Is there a difference in outcome between stage I-II endometrial cancer of papillary serous/clear cell and endometrioid FIGO Grade 3 cancer? Int. J. Radiat. Oncol. Biol. Phys. 2002; 54(1):79-85.

7. Ayeni TA, Bakkum-Gamez JN, Mariani A et al. Comparative outcomes assessment of uterine grade 3 endometrioid, serous, and clear cell carcinomas. Gynecol. Oncol. 2013; 129(3):478485 .

8. Bosse T, Peters EEM, Creutzberg CL et al. Substantial lymph-vascular space invasion (LVSI) is a significant risk factor for recurrence in endometrial cancer--A pooled analysis of PORTEC 1 and 2 trials. Eur. J. Cancer Oxf. Engl. 1990 2015; 51(13):1742-1750.

9. Creutzberg CL, van Putten WL, Koper PC et al. Surgery and postoperative radiotherapy versus surgery alone for patients with stage- 1 endometrial carcinoma: multicentre randomised trial. PORTEC Study Group. Post Operative Radiation Therapy in Endometrial Carcinoma. Lancet 2000; 355(9213):1404-1411.

10. Nout RA, Smit VTHBM, Putter H et al. Vaginal brachytherapy versus pelvic external beam radiotherapy for patients with endometrial cancer of high-intermediate risk (PORTEC-2): an open-label, non-inferiority, randomised trial. Lancet 2010; 375(9717):816-823.

11. Todo Y, Kato H, Kaneuchi M et al. Survival effect of para-aortic lymphadenectomy in endometrial cancer (SEPAL study): a retrospective cohort analysis. Lancet 2010; 375(9721):1165-1172.

12. Ballester M, Dubernard G, Lécuru $F$ et al. Detection rate and diagnostic accuracy of sentinelnode biopsy in early stage endometrial cancer: a prospective multicentre study (SENTIENDO). Lancet Oncol. 2011; 12(5):469-476.

13. Pecorelli S. Revised FIGO staging for carcinoma of the vulva, cervix, and endometrium. Int. J. Gynaecol. Obstet. Off. Organ Int. Fed. Gynaecol. Obstet. 2009; 105(2):103-104. 
14. Querleu D, Planchamp F, Narducci F et al. Clinical practice guidelines for the management of patients with endometrial cancer in France: recommendations of the Institut National du Cancer and the Société Française d'Oncologie Gynécologique. Int. J. Gynecol. Cancer Off. J. Int. Gynecol. Cancer Soc. 2011; 21(5):945-950.

15. Briët JM, Hollema $\mathrm{H}$, Reesink $\mathrm{N}$ et al. Lymphvascular space involvement: an independent prognostic factor in endometrial cancer. Gynecol. Oncol. 2005; 96(3):799-804.

16. Colombo N, Preti E, Landoni F et al. Endometrial cancer: ESMO Clinical Practice Guidelines for diagnosis, treatment and follow-up. Ann. Oncol. Off. J. Eur. Soc. Med. Oncol. ESMO 2013; 24 Suppl 6:vi33-38.

17. Vaizoglu F, Yuce K, Salman MC et al. Lymphovascular space involvement is the sole independent predictor of lymph node metastasis in clinical early stage endometrial cancer. Arch. Gynecol. Obstet. 2013; 288(6):1391-1397.

18. Weinberg LE, Kunos CA, Zanotti KM. Lymphovascular space invasion (LVSI) is an isolated poor prognostic factor for recurrence and survival among women with intermediate- to highrisk early-stage endometrioid endometrial cancer. Int. J. Gynecol. Cancer Off. J. Int. Gynecol. Cancer Soc. 2013; 23(8):1438-1445.

19. Altman AD, Ferguson SE, Atenafu EG et al. Canadian high risk endometrial cancer (CHREC) consortium: Analyzing the clinical behavior of high risk endometrial cancers. Gynecol. Oncol. $2015 ; 139(2): 268-274$.

20. Voss MA, Ganesan R, Ludeman L et al. Should grade 3 endometrioid endometrial carcinoma be considered a type 2 cancer-a clinical and pathological evaluation. Gynecol. Oncol. 2012; 124(1):15-20.

21. Bendifallah $\mathrm{S}$, Canlorbe $\mathrm{G}$, Collinet $\mathrm{P}$ et al. Just how accurate are the major risk stratification systems for early-stage endometrial cancer? Br. J. Cancer 2015. doi:10.1038/bjc.2015.35.

22. Hamilton $\mathrm{CA}$, Cheung MK, Osann $\mathrm{K}$ et al. Uterine papillary serous and clear cell carcinomas predict for poorer survival compared to grade 3 endometrioid corpus cancers. Br. J. Cancer 2006; 94(5):642-646.

23. Felix AS, Stone RA, Bowser R et al. Comparison of survival outcomes between patients with malignant mixed mullerian tumors and high-grade endometrioid, clear cell, and papillary serous endometrial cancers. Int. J. Gynecol. Cancer Off. J. Int. Gynecol. Cancer Soc. 2011; 21(5):877-884.

24. Greggi S, Mangili G, Cono Scaffa et al. Uterine papillary serous, clear cell, and poorly differentiated endometrioid carcinomas: a comparative study. Int. J. Gynecol. Cancer Off. J. Int. Gynecol. Cancer Soc. 2011; 21(4):661-667.

25. Bendifallah S, Canlorbe G, Raimond E et al. A clue towards improving the European Society of Medical Oncology risk group classification in apparent early stage endometrial cancer? Impact of lymphovascular space invasion. Br. J. Cancer 2014; 110(11):2640-2646.

26. Barlin JN, Soslow RA, Lutz M et al. Redefining stage I endometrial cancer: incorporating histology, a binary grading system, myometrial invasion, and lymph node assessment. Int. J. Gynecol. Cancer Off. J. Int. Gynecol. Cancer Soc. 2013; 23(9):1620-1628. 
27. Cancer Genome Atlas Research Network, Kandoth C, Schultz N et al. Integrated genomic characterization of endometrial carcinoma. Nature 2013; 497(7447):67-73.

28. Keys HM, Roberts JA, Brunetto VL et al. A phase III trial of surgery with or without adjunctive external pelvic radiation therapy in intermediate risk endometrial adenocarcinoma: a Gynecologic Oncology Group study. Gynecol. Oncol. 2004; 92(3):744-751.

29. Morice P, Leary A, Creutzberg C et al. Endometrial cancer. Lancet Lond. Engl. 2015. doi:10.1016/S0140-6736(15)00130-0.

30. Frumovitz M, Slomovitz BM, Singh DK et al. Frozen section analyses as predictors of lymphatic spread in patients with early-stage uterine cancer. J. Am. Coll. Surg. 2004; 199(3):388-393.

31. Ballester M, Koskas M, Coutant C et al. Does the use of the 2009 FIGO classification of endometrial cancer impact on indications of the sentinel node biopsy? BMC Cancer 2010; $10: 465$.

32. Achouri A, Huchon C, Bats AS et al. Complications of lymphadenectomy for gynecologic cancer. Eur. J. Surg. Oncol. J. Eur. Soc. Surg. Oncol. Br. Assoc. Surg. Oncol. 2013; 39(1):8186. 
$383 \quad$ Figures legends

384 Figure 1: Recurrence-free survival according to prognostic sub-group in the whole cohort $385 \quad(\mathbf{p}=\mathbf{0 . 0 0 0 5})$

386 Figure 2: Recurrence-free survival according to prognostic sub-group for type 1 EC $387 \quad(\mathbf{p}=\mathbf{0 . 0 0 0 6})$

$388 \quad$ Figure 3: Flow chart according to LVSI and lymph node status 
Table 1: Characteristics of the whole population

393

394

395

396

397

398

399

400

401

402

403

404

405

406

407

408

409

410

411

412

413

414

415

416

417

418

419

420

421

422

423

424

425

426

427

428

429

430

431

432

433

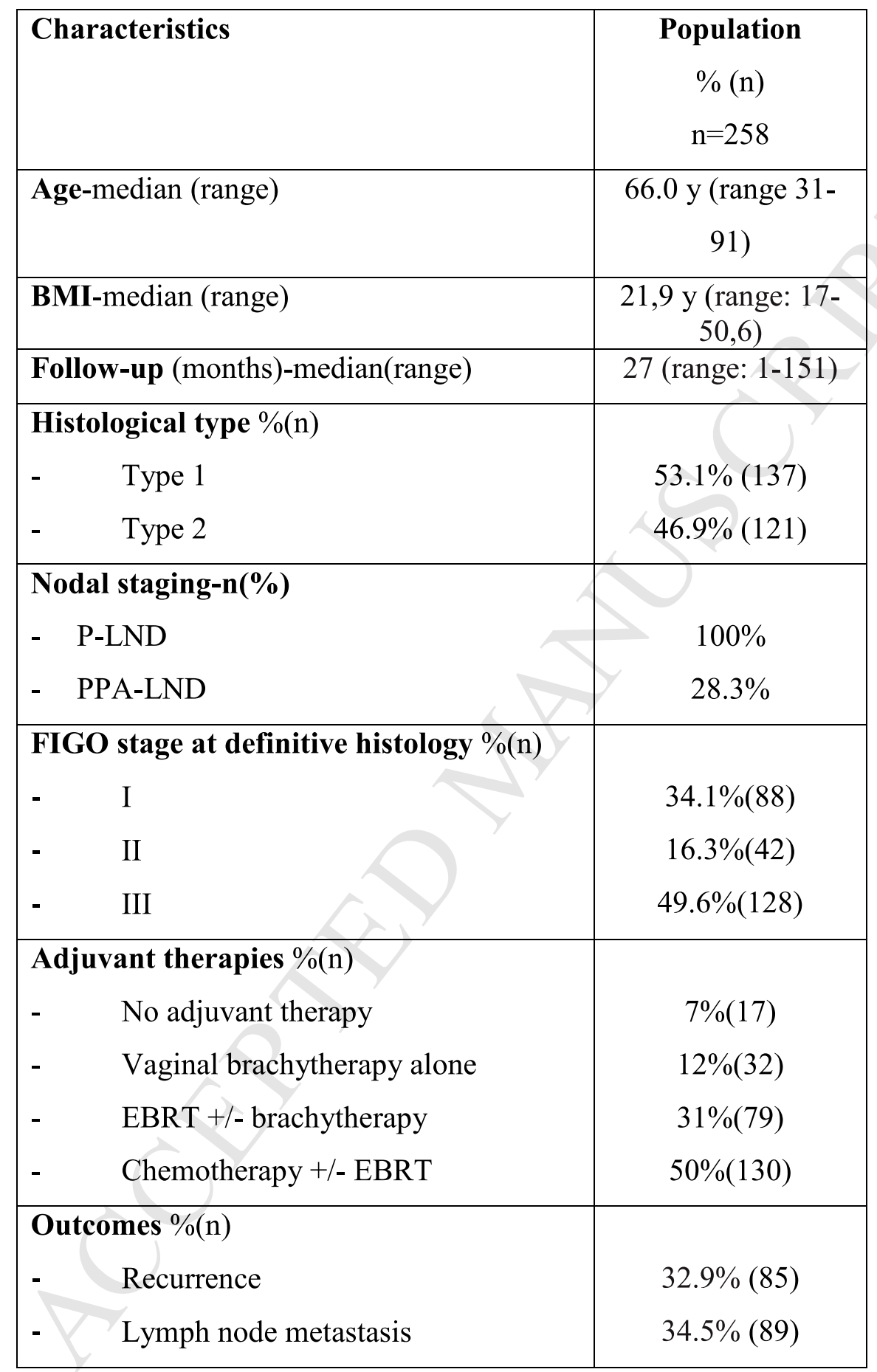

P-PA-LND : Pelvic / para-aortic Lymph Node Dissection, EBRT : external beam radiotherapy 


\begin{tabular}{|c|c|c|c|}
\hline & $\begin{array}{c}\text { No LVSI } \\
\mathrm{n}=131 \\
\mathrm{n}(\%)\end{array}$ & $\begin{array}{l}\text { LVSI } \\
\mathrm{n}=127 \\
\mathrm{n}(\%)\end{array}$ & $\mathrm{p}$ value \\
\hline Age-median (range) & $64.8(31-91)$ & $68.0(44-88)$ & 0.11 \\
\hline BMI-median (range) & $27.2(17-50.6)$ & $26.1(16.7-48.4)$ & 0.03 \\
\hline $\begin{array}{l}\text { Follow-up (months)- } \\
\text { median(range) }\end{array}$ & $31(1-151)$ & $23.5(1-116)$ & 0.008 \\
\hline $\begin{array}{l}\text { Histological type } \mathrm{n}(\%) \\
-\quad \text { Type } 1 \\
-\quad \text { Type } 2\end{array}$ & $\begin{array}{l}77(58.8) \\
54(41.2)\end{array}$ & $\begin{array}{l}60(47.2) \\
67(52.8)\end{array}$ & 0.0834 \\
\hline $\begin{array}{l}\text { Nodal staging-n (\%) } \\
-\quad \text { P-PA-LND } \\
-\quad \text { P-LND }\end{array}$ & $\begin{array}{l}26(19.8) \\
105(80.2)\end{array}$ & $\begin{array}{l}47(37.0) \\
80(63.0)\end{array}$ & 0.0034 \\
\hline Nodal metastases- $n(\%)$ & $23(17.6)$ & $66(52.0)$ & $<0.0001$ \\
\hline $\begin{array}{l}\text { Adjuvant therapies } n(\%) \\
-\quad \text { No adjuvant therapy } \\
\text { - } \quad \text { Vaginal brachytherapy } \\
\text { - } \quad \text { EBRT }+/- \\
\text { brachytherapy } \\
\text { - Chemotherapy }+/- \\
\text { EBRT }\end{array}$ & $\begin{array}{l}13(9.9) \\
24(18.3) \\
41(31.3) \\
53(40.5)\end{array}$ & $\begin{array}{c}4(3.1) \\
8(6.3) \\
38(30) \\
77(60.6)\end{array}$ & 0.0006 \\
\hline Recurrences-n(\%) & $31(23.7)$ & $54(42.5)$ & 0.0020 \\
\hline
\end{tabular}

Table 2: Comparison of epidemiological, surgical and histological characteristics of patients with and without LVSI at final histology.
437

438

439

440 
Table 3: Multivariate analysis of recurrence-free survival.

442

\begin{tabular}{|c|c|c|c|}
\hline \multirow{2}{*}{\multicolumn{2}{|c|}{ Covariates }} & \multicolumn{2}{|l|}{ RFS } \\
\hline & & HR 95\% CI & $\mathbf{P}$ \\
\hline \multicolumn{4}{|c|}{ Adjuvant therapies } \\
\hline- & Vaginal brachytherapy & Reference & \\
\hline- & Chemotherapy $+/-$ EBRT & $4.08(1.22-13.60)$ & 0.0218 \\
\hline- & EBRT +/- brachytherapy & $5.27(1.59-17.46)$ & 0.0065 \\
\hline- & No adjuvant therapy & $4.39(1.02-18.82$ & 0.0461 \\
\hline \multicolumn{4}{|c|}{ LVSI status } \\
\hline- & No & Reference & \\
\hline- & Yes & $2.07(1.27-3.34)$ & 0.0032 \\
\hline \multicolumn{4}{|c|}{ Lymph node status } \\
\hline- & No metastasis & Reference & \\
\hline- & Metastasis & $1.12(0.69-1.81)$ & 0.6446 \\
\hline \multicolumn{4}{|c|}{ Pathological types } \\
\hline - & Type 1 & Reference & \\
\hline- & Type 2 & $1.20(0.76-1.87)$ & 0.4220 \\
\hline
\end{tabular}

443

444

445 
Figure 1: Recurrence-free survival according to prognostic sub-group in the whole $\operatorname{cohort}(p=0.0005)$

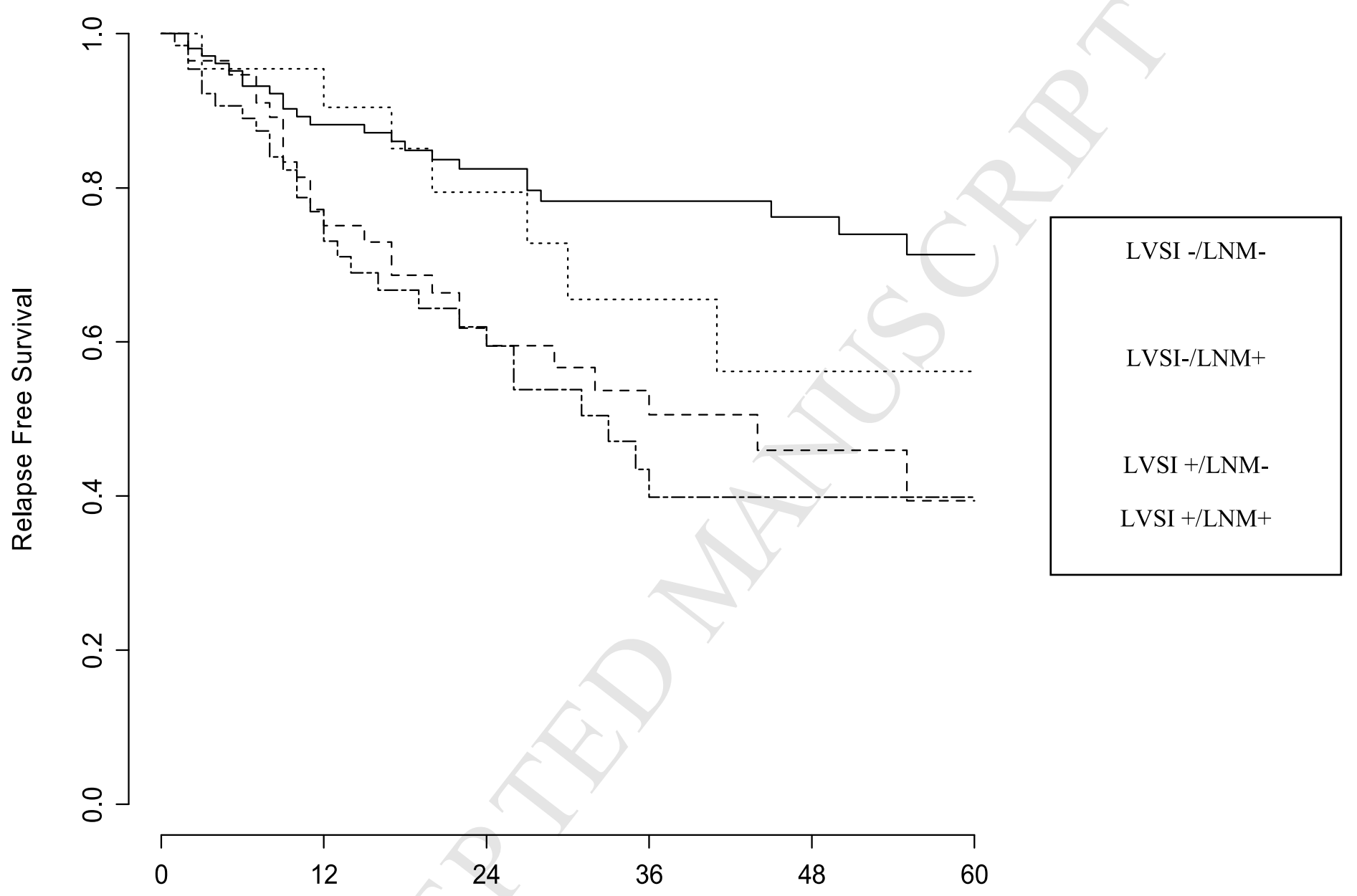

Time (months) 
Figure 2: Recurrence-free survival according to prognostic sub-group for type 1 EC $(p=0.0006)$

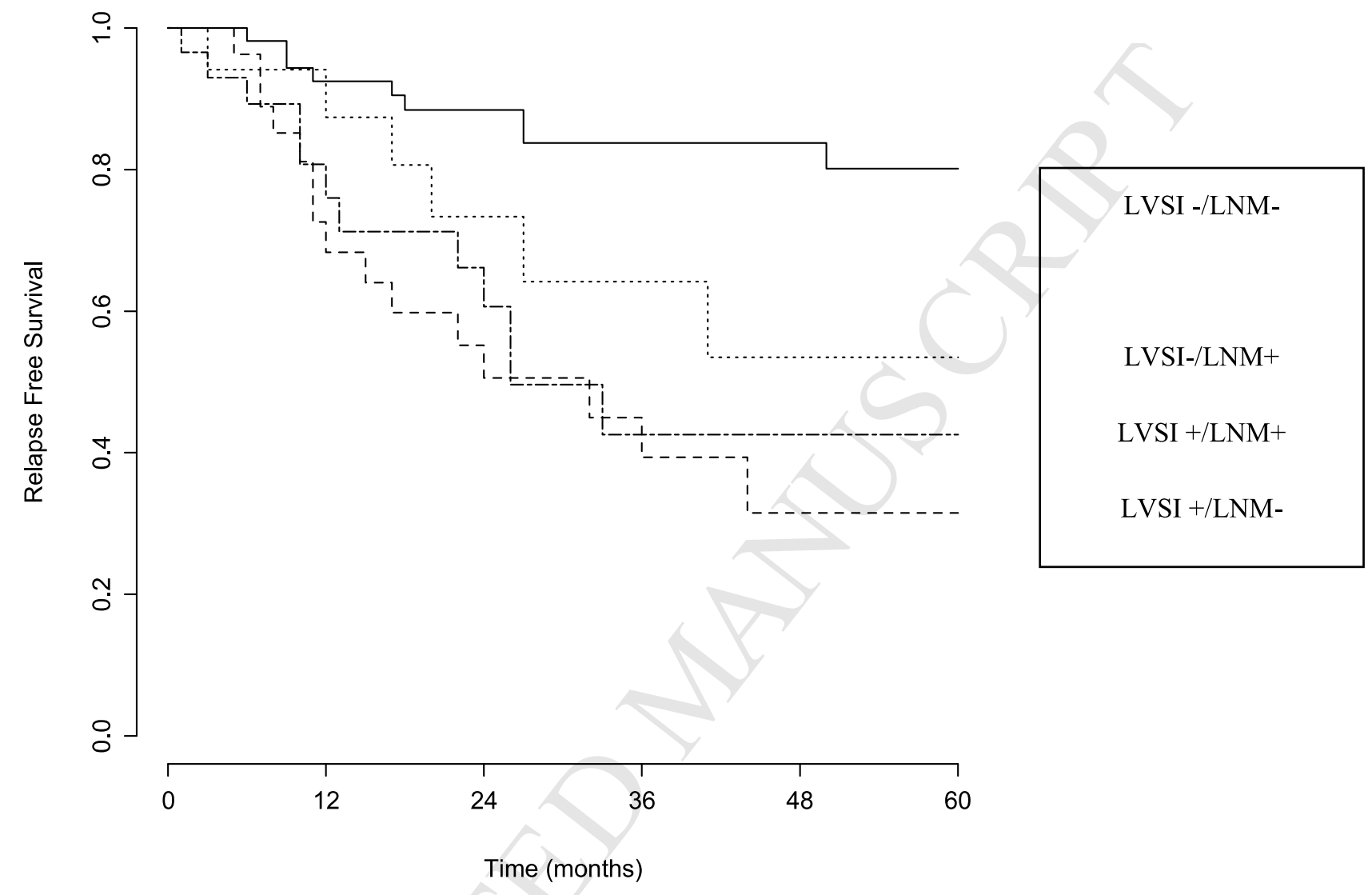




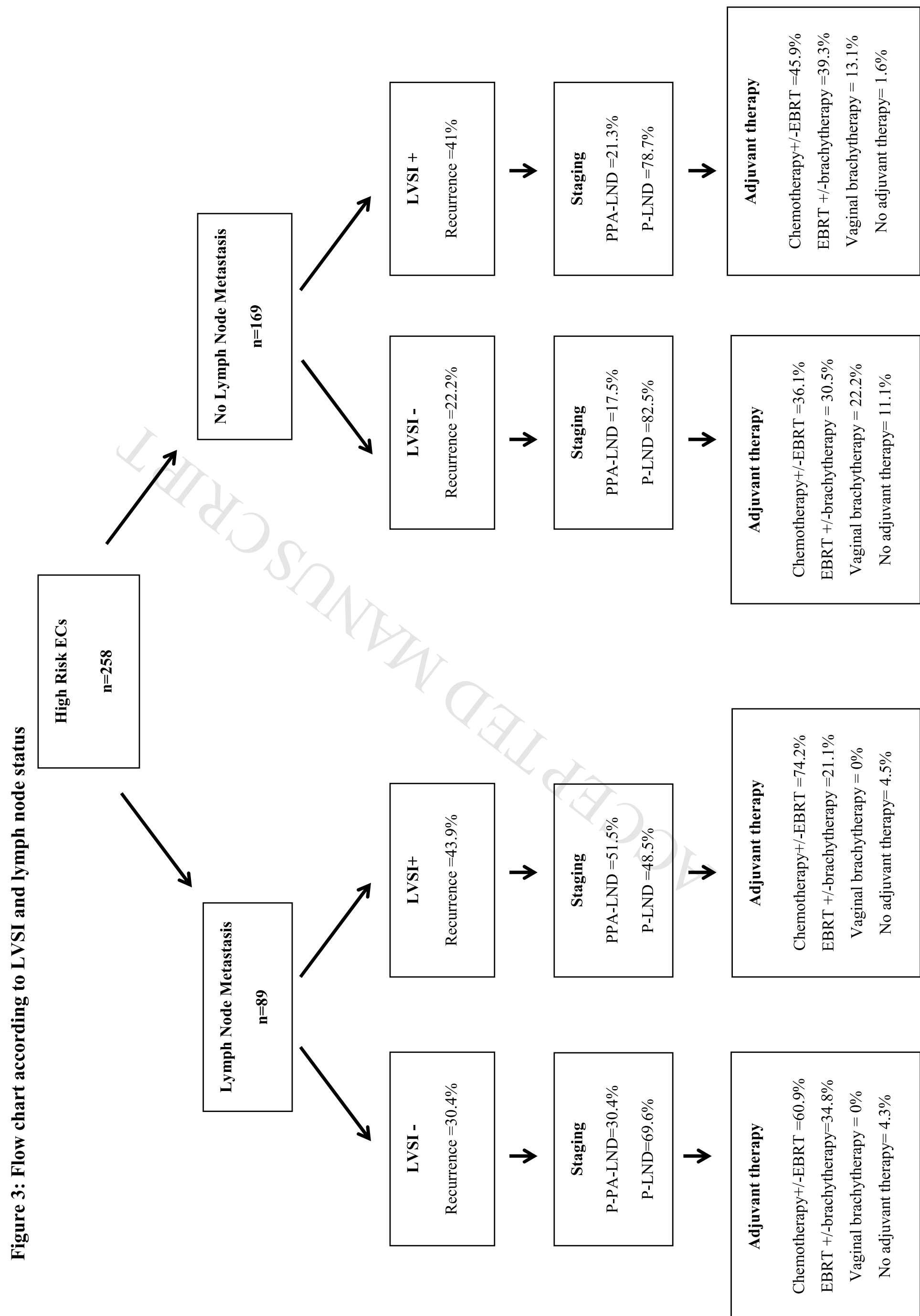

